\title{
INOVASI TEKNOLOGI INTEGRASI KAKAO-KAMBING PADA MODEL BIOINDUSTRI KAKAO TERHADAP PENINGKATAN PRODUKSI BUAH KAKAO DI KABUPATEN MAMAUJU
}

\section{An Innovation of Cocoa-Goat Integration Technology in Cocoa Bio-Industry Model for Increasing Cocoa Fruit Production in Mamuju Regency}

\author{
Ketut Indrayana*, Nini Kusrini, dan Muh. Ricky \\ Balai Pengkajian Teknologi Pertanian Sulawesi Barat \\ Jl. H. Abd. Pattana Endeng, Kabupaten Mamuju \\ *e-mail: ketutindrayanstp@gmail.com
}

Received: 20 September 2021; Accepted: 27 November 2021; Published: 25 Desember 2021

\begin{abstract}
ABSTRAK
Kakao merupakan komoditas unggulan daerah Sulawesi Barat, dan salah sentra penghasil kakao terbesar di Indonesia. Untuk mendapatkan model bioindustri yang baik, maka dirakit komponen-komponen dalam sistem integrasi antara kakao dengan ternak kambing. Hasil kegiatan yaitu Jumlah kelompok tani yang terlibat dalam kegiatan sebanyak 3 (tiga) kelompok dengan jumlah anggota petani sebanyak 27 orang. Tingkat pendidikan rata-rata dari SD - SMA dengan umur rata-rata 41,63 tahu. Lahan kakao anggota kelompok yang termasuk dalam kegiatan bioindustri seluas 35,25 ha dengan rata-rata kepemilikan 1,33 ha setiap anggota., 2) Pengelolaan kakao oleh anggota kelompok tani telah memproduksi atau menghasilkan biji kering kakao sebesar $38.092 \mathrm{~kg}$ dengan tingkat nilai penerimaan sebesar Rp. 1.142.760.000,- sedangkan pengelolaan ternak kambing oleh anggota kelompok tani telah memproduksi atau menghasilkan sebanyak 287 ekor dengan tingkat penerimaan dari hasil penjualan ternak sebesar Rp. 104.833.333,-.
\end{abstract}

Kata kunci: Bioindustri, model, kakao, integrasi, pendapatan

\section{ABSTRACT}

Cocoa is a leading commodity in West Sulawesi, and one of the largest cocoa producing centers in Indonesia. To get a good bio-industry model, components are assembled in an integrated system between cocoa and goats. The results of the activity are the number of farmer groups involved in the activity as many as 3 (three) groups with a total of 27 farmer members. The average level of education from elementary to high school with an average age of 41.63 years. Cocoa land of group members included in bio-industry activities is 35.25 ha with an average ownership of 1.33 ha for each member., 2) Cocoa management by farmer group members has produced or produced 38,092 $\mathrm{kg}$ of dry cocoa beans with an acceptance value of Rp. 1.142.760.000,- while the management of goats by members of farmer groups has produced or produced as many as 287 heads with a level of acceptance from livestock sales of Rp. 104,833,333.

Keywords: Bioindustry, model, cocoa, integration, income

\section{PENDAHULUAN}

Kementerian $\quad$ Pertanian $r$ telah
mengeluarkan Konsep Strategi Induk
Pembangunan Pertanian (SIPP) $2013-2045$, yaitu
konsep pembangunan pertanian berbasis
pertanian bioindustri, sebagai upaya memberikan
acuan dan arah pembangunan khususnya di

sektor pertanian ke depan. Simatupang (2014) mengemukakan bahwa perspektif sistem pertanian-bioindustri berkelanjutan meliputi: 1) Usaha pertanian berbasis ekonomi intensif (diversifikasi spasial dan temporal, integrasi tanaman-ternak-ikan), 2) pengolahan seluruh hasil pertanian dalam konsep biomassa- 
biorefinery, 3) Integrasi usaha pertanianbiodigester-biorefinery.

Konsep pertanian bioindustri tanpa limbah sebagai salah satu strategi untuk peningkatan nilai tambah dan daya saing serta kesejahteraan petani. Konsep ini, menuntut setiap lini produk mempunyai nilai jual, sehingga penggunan sumber daya menjadi efisien dan dapat menekan biaya produksi (Suswono, 2014). Melalui konsep zero waste, limbah dari budidaya tanaman diubah menjadi pakan ternak, dan produk turunan lainnya. Sebaliknya, limbah peternakan dapat digunakan sebagai pupuk/kompos, bio gas dan bio urine yang memungkinkan peningkatan nilai tambah di setiap rantai produksi. Sehingga petani akan memperoleh tambahan pendapatan.

Sulawesi Barat merupakan salah satu daerah penghasil kakao terbesar di Indonesia. Luas pertanaman Kakao di Sulawesi Barat pada tahun 2011 mencapai 175.860 ha dengan produksi 141.987 ton, produktivitasnya baru mencapai 0,81 t.ha (BPS Sulbar, 2012; Disbun Sulbar, 2012). Produktivitas baru mencapai 0,807 t/ha (BPS Sulbar, 2012). Pertanaman Kakao tersebar luas disemua kabupaten yang ada di Sulawesi Barat, yaitu Majene seluas 11.401 ha dengan produksi 7.976 ton, Polewali Mandar seluas 49.275 ha dengan produksi $35.185 \mathrm{t}$, Mamasa seluas 23.908 ha dengan produksi 17.159 t, Mumuju seluas 68.330 ha dengan produksi $26.870 \mathrm{t}$, dan Mamuju Utara seluas 22.946 ha dengan produksi $54.797 \mathrm{t}$ (BPS Sulbar, 2012; Disbun Sulbar 2011).

Beberapa permasalahan yang menyebabkan rendahnya produktivitas kakao di Sulawesi Barat antara lain masih tingginya serangan hama penyakit $(P B K, V S D)$, banyak tanaman tua, kesesuaian penggunaan lahan, dan masih rendahnya penerapan teknologi usahatani (Bappeda Sulbar, 2011, Disbun Sulbar, 2012). Masalah tersebut akan berdampak pada rendahnya pendapatan petani Kakao di Sulawesi Barat. Disisi lain terdapat banyak sumber pendapatan yang bisa dikelolah untuk meningkatkan pendapatan petani kakao antara lain limbah kakao yang melimpah belum dimanfaatkan secara maksimal menjadi pupuk kompos. Produk-produk turunan (sekunder) dari kakao belum banyak dikembangkan misalnya nata decocoa, bubuk coklat, coklat pasta, dan lain-lain. Selain itu sudah banyak juga petani kakao yang melakukan usahatani ternak kambing di areal pertanaman kakao. Disisi lain limbah ternak kambing yang ada belum dimanfaatkan secara maksimal untuk dijadikan pupuk kompos dan biourine untuk digunakan di areal pertanaman. Begitu pula limbah buah kakao belum dimanfaatkan secara maksimal untuk dijadikan pakan ternak kambing.

Integrasi kakao dengan ternak kambing berpeluang meningkatkan produktivitas dan mutu hasil kakao. Terdapat sinergi positif dalam pengembangan program bioindustri (integrasi kakao-kambing) pada kawasan sentra kakao antara lain adalah terjadinya efisiensi dalam usahatani kakao, produktivitas tanaman akan meningkat baik kualitas maupun kuantitas karena tersedianya pupuk organik yang diproduksi oleh kambing. Sebaliknya untuk ternak kambing adanya jaminan ketersediaan suplai pakan yang bersumber dari limbah kulit buah kakao, pangkasan kakao, pangkasan tanaman penaung dan gulma kebun. Berdasarkan beberapa uraian permasalahan diatas maka perlu dilakukan suatu terobosan untuk mengintegrasikan semua permasalahan dan potensi usahatani kakao serta mengoptimalkan pemanfaatan semua sumberdaya yang tersedia untuk meningkatkan produktivitas, mutu kakao, pendapatan petani kakao serta usahatani ramah lingkungan melalui Pengembangan Model Pertanian Bioindustri Kakao di Sulawesi Barat. Tujuan yang ingin dicapai adalah mengetahui peningkatan produksi buah kakao melalui penerapan inovasi teknologi integrasi kakao-kambing pada model bioindustri kakao Di Kabupaten Mamuju.

\section{METODE PENELITIAN}

\section{Rancangan Penelitian}

Penelitian dilakukan dengan metode studi kasus, karena peneliti ingin melakukan proses analisis secara mendalam terhadap satu obyek yakni pada kelompok tani bioindustri kakao di Desa Salubara'na Kecamatan Sampaga, Kabupaten Mamuju.

\section{Metode Penentuan Sampel}

Penentuan sampel dilakukan secara sengaja yakni kelompok tani bioindustri kakao, dengan pertimbangan bahwa kelompok tersebut yang telah menerapkan system integrase Kambing-Kakao sebenyak 27 petani, yang tersebar dalam 3 kelompok tani, yakni kelompok 
Tani Rahmat, Kelompok Tani Harapan Baru, dan kelompok Tani

\section{Jenis dan Sumber Data}

Jenis dan sumber data yang digunakan dalam penelitian ini adalah data primer dan data sekunder. Proses pengambilan data primer yang dilaksanakan adalah melalui wawancara dengan kelompok tani bioindustri kakao. Data sekunder dikumpulkan melalui informasi sebagai pendukung data primer, diperoleh dari media internet, buku-buku, laporan tertulis, penelitianpenelitian terdahulu dan jurnal yang berhubungan dengan penelitian serta lembaga-lembaga atau instansi terkait dengan penelitian.

\section{Teknik Pengumpulan Data}

Teknik pengumpulan data yang digunakan dalam penelitian ini, yaitu: 1. Metode observasi yaitu metode pengumpulan data dengan melakukan pengamatan langsung terhadap obyek yang akan diteliti sehingga didapatkan gambaran yang jelas mengenai obyek yang akan diteliti. 2. Metode wawancara yaitu metode pengambilan data dengan wawancara secara luas dan mendalam dengan responden sampel dengan menggunakan daftar pertanyaan (kuisioner) yang telah dipersiapkan. 3. Metode pencatatan yaitu metode pengumpulan data dengan melakukan pencatatan data dari segala sumber yang berkaitan dengan penelitian.

\section{Metode Analisis Data}

Analisis data dilakukan secara deskriptif kuantitatif, data hasil penelitian dianalisis untuk mengetahui peningkatan produksi buah kakao yang dihasilkan dengan penerapan inovasi teknologi integrase kakao-kambing di Desa Salubara'na Kecamatan Sampaga, Kabupaten Mamuju.

\section{HASIL DAN PEMBAHASAN}

\section{Karakteristik Petani Bioindustri Kakao di Sulawesi Barat}

Karakteristik personal setiap manusia berbeda-beda antara satu dengan yang lain. Karakteristik merupakan ciri atau kemampuan untuk memperbaiki kualitas hidup (Kamus Besar Bahasa Indonesia/KBBI). Karakteristik individu dapat menjadi pembeda yang khas antara individu dengan individu lainnya. Karakteristik personal petani disajikan pada Tabel 1 .

Tabel 1. Karakteristik petani bioindustri kakao di Sulawesi Barat.

\begin{tabular}{lllcc}
\hline \multirow{2}{*}{ No } & \multicolumn{1}{c}{ Uraian } & \multicolumn{1}{c}{ Kategori } & $\mathrm{n}$ & $\%$ \\
\hline 1 & Umur (tahun) & $18-29$ (Muda) & 6 & 22,22 \\
& & $30-50$ (Dewasa) & 15 & 55,56 \\
& & $>50$ (Tua) & 6 & 55,56 \\
& Jumlah & $0-9$ (Rendah) & 27 & 100 \\
\hline 2 & Pendidikan Formal (Tahun) & $10-13$ (Sedang) & 21 & 77,78 \\
& & $>13$ (Tinggi) & 6 & 22,22 \\
& & $0-1$ (Rendah) & 27 & 0 \\
& Jumlah & $2-3$ (Sedang) & 0 & 100 \\
\hline 3 & Jumlah Tanggungan (Jiwa) & $>3$ (Tinggi) & 11 & 0 \\
& & $0-0,5$ (Sempit) & 16 & 40,74 \\
& & $0,6-1$ (Sedang) & 27 & 59,26 \\
& Jumlah & $>1$ & 0 & 0 \\
\hline 4 & Luas Lahan (Ha) & & 14 & 51,85 \\
& & & 27 & 48,15 \\
& Jumlah & & & 100 \\
\hline
\end{tabular}

Tabel 1 menunjukkan bahwa 55,56\%, atau sebanyak 15 petani responden berada pada kategori umur dewasa yakni antara umur 30-50 tahun. Hal ini juga menunjukkan bahwa mayoritas petani masih berada pada usia produktif. Umur akan mempengaruhi seseorang dalam merespon sesuatu yang baru walaupun belum banyak mempunyai pengalaman. Petani 
dengan umur produktif atau dewasa biasanya mempunyai semangat untuk ingin tahu tentang berbagai hal yang belum diketahui dan cenderung tinggi adopsi inovasinya, karena kekuatan fisik dan kematangan psikologisnya saling mendukung. Selain itu usia juga mempengaruhi kemampuan fisik bekerja dan cara berpikir responden. Disamping itu, umur juga mempengaruhi kinerja responden dalam mengelola usahataninya. Terkait dengan adanya inovasi, seseorang pada umur non produktif akan cenderung sulit menerima inovasi (Krisnawati, 2014).

Karakteristik pendidikan petani bioindustri cukup beragam dan tidak ada yang berpendidikan tinggi atau sarjana. Tingkat pendidikan petani bioindustri berada pada kategori rendah, dimana sebesar 77,78\% (21 responden) memiliki tingkat pendidikan 0-9 tahun. Dari gambaran tingkat pendidikan yang dimiliki oleh patani bioindustri kakao tersebut menunjukkan bahwa kaulitas SDM petani masih rendah atau lemah, yang dapat berimplikasi terhadap lambatnya adopsi inovasi teknologi yang diterapkan dalam kegiatan bioindustri kakao tersebut. Memahami kondisi tersebut, maka pada kegiatan bioindustri kakao melakukankegiatan-kegiatan yang dapat meningkatkan kualitas SDM petani melalui pendidikan non formal seperti pelatihan pemangkasan, pembuatan dan pemupukan organik, pemeliharaan kambing, pembuatan biourine kambing, pengendalian hama penyakit, sanitasi lahan dengan sistem rorak serta peningkatan kualitas biji kakao melalui pelatihan fermentasi biji sesuai standar mutu SNI.

Variable jumlah tanggungan menujukkan bahwa $59,26 \%$ petani (16 petani responden) kakao memiliki jumlah tanggungan yang tinggi yakni diatas 3 jiwa. Tanggungan keluarga merupakan salah satu sumberdaya manusia pertanian yang dimiliki petani, terutama yang beusia produktif. Namun tanggungan keluarga juga bisa menjadi beban hidup keluarga apabila tidak membantu dalam usahataninya (Syafruddin 2003). Namun banyaknya jumlah tanggungan yang dimiliki oleh seseorang juga mampu menjadi motivasi untuk lebih memberbaiki system usahatani yang dilakukan.

Secara umum petani responden memiliki lahan yang luas yakni di atas $1 \mathrm{Ha}$. Total areal lahan kakao anggota kelompok tani yang tergabung dalam kegiatan bioindustri seluas
35,25 ha atau rata-rata 1,31 ha setiap anggota. Lahan kakao yang termasuk dalam kegiatan bioindustri secara keseluruhan telah berproduksi. Rata-rata umur kakao sekitar 5,0 - 12 tahun. Varietas atau klon kakao yang ditanam umumnya klon Sulawewsi 1 (S-1) dan Sulawesi 2 (S2). Kolon-klon tersebut merupakan klon kakao yang telah beradaptasi baik secara spesifik di wilayah pengembangan kakao khususnya di wilayah Mamuju. Klon S-1 dan S-2 memilki potensi hasil yang tinggi yaitu $1,8-2,5 \mathrm{t} / \mathrm{ha}$.

\section{Hasil Komponen Pengelolaan Tanaman Kakao}

\section{Produksi biji dan kulit buah kakao}

Panen buah tanaman kakao dilakukan seringkali yaitu $4-5$ kali pada masa berbuah (panen sering), panen sering biasanya dilakukan pada buah-buah yang sudah tua tetapi hanya 1 - 2 buah setiap pohonnya. Puncak panen biasanya disebut panen raya yang ditandai dengan buah pada pohon seluruhnya menunjukkan siap panen. Panen raya merupakan waktu panen buah dengan produksi tertinggi. Panen raya pada lahan kakao kelompok tani bioindustri biasanya berlangsung pada bulan Mei - juni dan bulan Oktober November setiap tahunnya. Produksi buah dan biji total kakao kelompok tani pada periode panen I (pertama) periode bulan Januaril - Juli dan panen II (kedua) periode bulan Agustus Desember 2017, disajikan pada Tabel 2.

Pada Tabel 2, tampak bahwa kepemilikan lahan kakao dari 27 anggota yang tergabung dalam tiga kelompok, memiliki luas lahan kakao yang beragam dengan total luas sebesar 35,25 ha atau rata-rata 1,31 ha setiap anggota. Rata-rata tingkat kepemilikan lahan terluas berada pada anggota kelompok tani Rahmat kemudian kelompok tani Sipatu dan Harapana Baru dengan tingkat kepemilikan lahan masing-masing berturut-turut $1,5 \mathrm{ha}, 1,4$ ha dan 1,03 ha.

Total hasil produksi biji kakao kering siap jual yang diperoleh kelompok tani bioindustri pada tahun 2017 sebanyak $38.092 \mathrm{~kg}$ (Tabel 2). Hasil tersebut berasal dari hasil panen lahan kakao seluas 35,25 ha yang dikelola oleh sebanyak 27 petani dari 3 kelompok tani yang bergabung. Hasil biji kering tersebut diperoleh dari gabungan atau total akumulasi hasil panen ke-I sebanyak $14.485 \mathrm{~kg}$ dan akumulasi hasil panen ke-II sebanyak $23.607 \mathrm{~kg}$. 
Tabel 2. Produksi biji dan kulit buah kakao kelompok tani Bioindustri

\begin{tabular}{|c|c|c|c|c|c|c|c|}
\hline \multirow{2}{*}{ No. } & \multirow{2}{*}{$\begin{array}{l}\text { Nama Keltan/ } \\
\text { Anggota }\end{array}$} & \multirow{2}{*}{$\begin{array}{l}\text { Luas lahan } \\
\text { Kakao (ha) }\end{array}$} & \multicolumn{3}{|c|}{ Produksi (kg) } & \multirow{2}{*}{$\begin{array}{l}\text { Produksi } \\
\text { KBK (ton) }\end{array}$} & \multirow{2}{*}{$\begin{array}{l}\text { Nilai hasil biji } \\
\text { (Rp) }\end{array}$} \\
\hline & & & Panen II & Panen I & Total & & \\
\hline \multicolumn{8}{|c|}{ A. Rahmat } \\
\hline 1. & M. Ismail & 1,50 & 800 & 750 & 1.550 & 131,75 & 46.500 .000 \\
\hline 2. & Siswanto & 1,50 & 700 & 740 & 1.440 & 122,4 & 43.200 .000 \\
\hline 3. & Amiruddin & 1,50 & 600 & 760 & 1.360 & 115,6 & 40.800 .000 \\
\hline 4. & Ridwan Gani & 2,00 & 500 & 1.000 & 1.500 & 127,5 & 45.000 .000 \\
\hline 5. & Rauf & 1,50 & 1.000 & 750 & 1.750 & 148,75 & 52.500 .000 \\
\hline 6. & Sirajuddin & 1,00 & 900 & 400 & 1.300 & 110,5 & 39.000 .000 \\
\hline 7. & Markus & 1,50 & 700 & 650 & 1.350 & 114,75 & 40.500 .000 \\
\hline 8. & Yasin & 1,50 & 900 & 600 & 1.500 & 127,5 & 45.000 .000 \\
\hline 9. & Muhiddin & 1,50 & 900 & 625 & 1.525 & 129,625 & 45.750 .000 \\
\hline 10. & Mahmud & 1,50 & 1.500 & 620 & 2.120 & 180,2 & 63.600 .000 \\
\hline \multirow[t]{3}{*}{11.} & Junaidi & 1,50 & 700 & 750 & 1.450 & 123,25 & 43.500 .000 \\
\hline & Jumlah & 16,5 & 9.200 & 7.645 & 16.845 & $1.432,83$ & 505.350 .000 \\
\hline & Rata-rata & 1,5 & 557,58 & 463,33 & 1.021 & 130,17 & 45.940 .909 \\
\hline B. & Harapan Baru & & & & & & \\
\hline 12. & Junaid & 1,00 & 957 & 350 & 1.307 & 111,10 & 39.210 .000 \\
\hline 13. & Muhammad & 0,75 & 500 & 350 & 850 & 72,25 & 25.500 .000 \\
\hline 14. & Sirajuddin & 1,00 & 650 & 250 & 900 & 76,50 & 27.000 .000 \\
\hline 15. & Mustaim & 1,00 & 600 & 500 & 1.100 & 93,50 & 33.000 .000 \\
\hline 16. & Kamaruddin & 1,00 & 1.000 & 250 & 1.250 & 106,25 & 37.500 .000 \\
\hline 17. & Irmawansah & 1,00 & 900 & 200 & 1.100 & 93,50 & 33.000 .000 \\
\hline 18. & Joris & 0,75 & 600 & 350 & 950 & 80,75 & 28.500 .000 \\
\hline 19. & Lukman & 1,00 & 700 & 475 & 1.175 & 99,88 & 35.250 .000 \\
\hline 20. & Baharuddin & 0,75 & 400 & 350 & 750 & 63,75 & 22.500 .000 \\
\hline \multirow[t]{3}{*}{21.} & Tandi & 2,00 & 2.000 & 750 & 2.750 & 233,75 & 82.500 .000 \\
\hline & Jumlah & 10,25 & 8.307 & 3.825 & 12.132 & $1.031,22$ & 363.960 .000 \\
\hline & Rata-Rata & 1,03 & 810,44 & 373,17 & 1.184 & 103,12 & 36.396 .000 \\
\hline $\mathrm{C}$. & Sipatuo & & & & & & \\
\hline 22. & Saharuddin & 2,50 & 1.300 & 1,100 & 2.400 & 204 & 72.000 .000 \\
\hline 23. & Sahril & 1,00 & 300 & 720 & 1.020 & 86.7 & 30.600 .000 \\
\hline 24. & Jahari & 2,00 & 2.000 & 250 & 2.250 & 191.25 & 67.500 .000 \\
\hline 25 & Nanang. S & 1,00 & 500 & 650 & 1.150 & 97.75 & 34.500 .000 \\
\hline 26. & Dahlan & 1,00 & 1.000 & 120 & 1.120 & 95.2 & 33.600 .000 \\
\hline \multirow[t]{3}{*}{27.} & M. Ilham & 1,00 & 1.000 & 175 & 1.175 & 99.875 & 35.250 .000 \\
\hline & Jumlah & 8,50 & 6100 & 3.015 & 9115 & 774.78 & 273.450 .000 \\
\hline & Rata-Rata & 1,42 & 717,65 & 354,71 & 1,072 & 129.13 & 45.575 .000 \\
\hline \multicolumn{2}{|c|}{ JUMLAH TOTAL } & 35,25 & 23.607 & 14.485 & 38.092 & $3.237,82$ & 1.142 .760 .000 \\
\hline \multicolumn{2}{|c|}{ RATA-RATA } & 1,31 & 669,70 & 410,92 & 1.081 & 119,92 & 42.324 .444 \\
\hline
\end{tabular}

Keterangan: Harga biji kakao kering Rp. 30.000/kg. 
Kelompok tani yang memperoleh hasil biji kering tertinggi secara berurutan adalah kelompok tani "Rahmat", kemudian kelompok tani "Harapan Baru" dan "Sipatuo". Berdasarkan hasil pengamatan dan data yang diperoleh menunjukkan bahwa produksi biji yang dihasilkan kelompok ditentukan oleh luas lahan usahatani kakaonya, sehingga kelompok tani yang memiliki lahan kakao terluas memberikan jumlah produksi biji kering paling banyak, meskipun produktivitasnya berbeda pada setiap kelompok tani. Kelompok tani "Rahmat" memiliki lahan kakao anggota kelompok seluas 16,5 ha, sedangkan kelompok tani "Harapan Baru" dan "Sipatuo" masing-masing hanya memiliki lahan seluas 10,25 ha dan 8,5 ha. Kelompok yang memberikan produktivitas hasil kakao tertinggi adalah kelompok "Harapan Baru" dengan produktivitas sebesar $1.184 \mathrm{~kg} / \mathrm{ha}$, kemudian kelompok tani Sipatu dan Rahmat dengan produktivitas masing-masing $1.072 \mathrm{~kg} / \mathrm{ha}$ dan 1.021 ha.

Produksi biji kakao kelompok tani bioindustri yang diperoleh merupakan sumber utama pendapatan anggota kelompok tani yang terlibat. Nilai hasil produksi biji kering kakao petani yang diperoleh total sebanyak Rp. 1.142.760.000,- (Tabel 2). Nilai produksi tersebut diperoleh dari total produksi seluruh kelompok sebanyak $38.092 \mathrm{~kg}$ dengan harga jual ditingkat pedagang lokal seharga Rp. 30.000/kg. Jika dirata-ratakan, maka tingkat pendapatan kotor setiap anggota kelompok (petani) dari hasil penjualan produksi biji kering kakao sebesar Rp. 42.324.444/anggota. Tingkat pendapat tersebut tergolong cukup tinggi karena hanya diperoleh usahatani kakao, dan sumber tambahan pendapatan masih ada dari pengelolaan produksi bibit kakao, pengelolaan ternak kambing serta penjualan hasil industri pengolahan limbah. Kelompok tani bioindustri yang mempunyai pendapatan tertinggi hasil penjualan biji kering kakao adalah adalah kelompok tani "Rahmat" kemudian "Harapan Baru" dan Sipatuo. Tingkat penerimaan nilai hasil penjualan tertinggi ditentukan oleh besarnya produksi biji kering kakao yang dihasilkan. Semakin banyak produksi yang dimiliki maka pendapatan atau penerimaannya semakin besar.

Dalam pengolahan hasil buah kakao, akan diperoleh kulit buah kakao (KBK) yang cukup tinggi sebab $80-85 \%$ dari merupakan kulit buah dan hanya $15-20 \%$ yang merupakan biji. Kulit buah kakao secara umum pada petani yang tidak termasuk dalam kelompok bioindustri tidak memanfaatkannya, sehingga hanya menjadi limbah, dimana jika dibuang disekitar atau dalam lahan tanaman kakao akan menjadi sumber dan sarang hama penyakit seperti PBK dan VSD. Pada kegiatan bioindustri kakao yang dilakukan, KBK merupakan potensi sumber pakan dan bahan baku pupuk organik, serta menjadi bagian atau komponen dari sistem dalam bioindustri yang dilakukan. KBK akan dioleh menjadi pakan potensial untuk ternak kambing anggota kelompok. Dari produksi buah kakao yang ada pada setiap lahan anggota kelompok tani diperoleh KBK sebanyak 3.237,82 ton (Tabel 2). Semakin tinggi produksi buah maka KBK yang dihasilkan semakin banyak. Kelompok tani bioindustri yang memproduksi KBK terbanyak adalah kelompok tani "Rahmat" kemudian kelompok tani "Harapan Baru" dan Sipatuo. Proses pengolahan KBK menjadi pakan dan sebagai sumber bahan pupuk organic akan dilakukan pada tahun 2017.

\section{KESIMPULAN}

1. Jumlah kelompok tani yang terlibat dalam kegiatan sebanyak 3 (tiga) kelompok dengan jumlah anggota petani sebanyak 27 orang. Dengan karakteristik personal sebagai berikut: $55,56 \%$, atau sebanyak 15 petani responden berada pada kategori umur dewasa yakni antara umur 30-50 tahun. Hal ini juga menunjukkan bahwa mayoritas petani masih berada pada usia produktif. Tingkat pendidikan responden berada pada ketegori rendah, jumlah tanggungan tinggi dan luas lahan juga berada pada kategori luas.

2. Pengelolaan kakao oleh anggota kelompok tani telah memproduksi atau menghasilkan biji kering kakao sebesar $38.092 \mathrm{~kg}$ dengan tingkat nilai penerimaan sebesar Rp. 1.142.760.000,- sedangkan pengelolaan ternak kambing oleh anggota kelompok tani telah memproduksi atau menghasilkan sebanyak 287 ekor dengan tingkat penerimaan dari hasil penjualan ternak sebesar $\mathrm{Rp}$. 104.833.333,-

\section{SARAN}

Diperlukan analisis lebih menalam terkait analisis pendapatan petani ternak dengan menggunakan model integrase kambing kakao di 
Desa Salubara'na Kecamatan Sampaga, Kabupaten Mamuju.

\section{DAFTAR PUSTAKA}

Adnyana, M.O. 2005. Pengembangan sistem integrasi tanaman-ternak bebas limbah di KP Muara. Pusat Penelitian dan Pengembangan Tanaman Pangan, Bogor.

Adnyana, M.O., A.K. Makarim, U.D.Djaenudin, I G.M. Subiksa, B. Haryanto,Marwan, dan R. Tjahjohutomo. 2007. Master Plan dan Business Plan Merauke Integrated Rice Estate (MIRE), Kabupaten Merauke, Papua.

Bamualim, A., Kuswandi, A. Azahari, dan B. Haryanto. 2008. Sistem Usahatani Tanaman-Ternak. hlm 19-33. Dalam Sistem Integrasi Tanaman PanganTernak Bebas Limbah. Pusat Penelitian dan Pengembangan Tanaman Pangan,Bogor.

Diwyanto, K. dan B. Haryanto. 1999. Pembangunan pertanian ramah lingkungan: Prospek pengembangan ternak pola integrasi (Suatu konsep pemikiran dan bahan diskusi). Pusat Penelitian dan Pengembangan Peternakan,Bogor.

Diwyanto, K. dan E. Handiwirawan. 2004. Peran Litbang dalam mendukung usaha agribisnis pola integrasi tanamanternak. Pros. Seminar Nasional Sistem Integrasi Tanaman-Ternak. Denpasar, 20 - 22 Juli 2004. Puslitbang Peternakan bekerjasama dengan BPTP dan CASREN. hlm. $63-80$.

Guntoro S. 2011. Saatnya Menerafkan Pertanian Tekno-Ekologis. Sebuah Model Pertanian Masa Depan untuk Menyikapi Perubahan Iklim. PT. Agromedia Pustaka

Krisnawati, 2014. Persepsi Petani Terhadap Peranan Penyuluh Pertanian Di Desa Sidomulyo Dan Muari Distrik Oransbari Kabupaten Manokwari Selatan. [Tesis]. Institut Pertanian Bogor. Bogor.

Simatupang, P. 2014. Perspektif Pertanian Bioindustri Berkelanjutan. Dalam Haryono, dkk (Editor). Reformasi Kebijakan Menuju Transformasi Pembangunan Pertanian. Kementerian Pertanian. IAARD Press.

Suswono 2014a. Sektor Pertanian Akan Menjadi Bio Industri Sabtu, 25 Januari 2014 16:32 wib | Dani Jumadil Akhir economy.Okezone.com

Suswono 2014 ${ }^{\mathrm{b}}$. Menteri pertanian gagas bioindustri di pedesaan. Jakarta. kabarbisnis.com, Rabu (19/3/2014). 